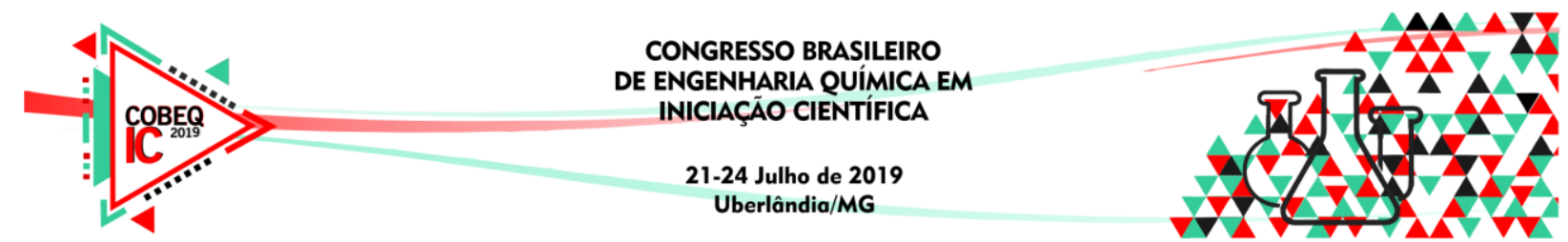

\title{
AVALIAÇÃO DA ADIÇÃO DE GLICEROL E DIFERENTES SAIS NO EQUILÍBRIO LÍQUIDO-VAPOR DO SISTEMA ISOPROPANOL-ÁGUA
}

\author{
I. B. JULIÃO ${ }^{1}$ e M. F. MENDES ${ }^{1}$ \\ ${ }^{1}$ Universidade Federal Rural do Rio de Janeiro, Departamento de Engenharia Química, Brasil \\ E-mail para contato: marisamf@ufrrj.br
}

\begin{abstract}
RESUMO - O isopropanol é largamente utilizado em processos industriais como solvente de processos, insumo químico, agente de limpeza e secagem de equipamentos eletrônicos e mecânicos. Há diversos métodos de produção industrial do álcool mas, em muitos deles, é necessária a purificação para obtenção de uma fração mais pura de isopropanol. Isso não ocorre por destilação simples, visto que o mesmo forma um azeótropo com a água. Nesse caso, é necessário a utilização da destilação extrativa, onde é adicionado um terceiro componente, o qual interfere no equilíbrio líquido-vapor do sistema, permitindo a separação do componente mais volátil. Com base nisso, este trabalho tem o objetivo de avaliar o comportamento do equilíbrio líquido-vapor (ELV), realizando medidas experimentais a pressão normal, para o sistema ternário isopropanol-água e um terceiro componente. Foram escolhidos o glicerol e os sais acetato de potássio e de sódio, visto que os mesmos já foram utilizados para a "quebra" do azeótropo do sistema etanol-água. Para este trabalho foram utilizadas as frações mássicas de 10 e $20 \%$ para o glicerol, $5 \%$ para o acetato de sódio e 5 e $10 \%$ para o acetato de potássio. Foi constatado que os sais de acetato foram capazes de enriquecer a fase vapor em álcool. Já o glicerol, além de ser capaz de quebrar o azeótropo, apresentou o melhor resultado utilizando a fração mássica de $20 \%$, revelando-se um bom solvente para o mercado sustentável.
\end{abstract}

\section{INTRODUÇÃO}

O álcool isopropílico é amplamente utilizado em processos industriais e sua produção mundial é de aproximadamente 2,7 milhões de toneladas por ano, produzidas principalmente pelos Estados Unidos e Ásia. É utilizado principalmente para as indústrias Farmacêutica, Cosmética e Petroquímica, sendo utilizado como solvente, reagente e até mesmo agente de limpeza, pois sua produção com uma fração muito pequena de água é ideal para a limpeza de componentes eletrônicos. Sua síntese industrial possui diversos métodos, sendo os mais comuns a formação a partir da acetona e a hidratação do propeno. Estes e outros atingem uma solução com alto grau de pureza, muitas vezes superior a 90\% (Gomes, 2016).

Todavia, a mistura isopropanol-água forma um azeótropo, que impede a completa separação dessa mistura por métodos convencionais, como a destilação simples. Assim, técnicas mais específicas são empregadas, como a destilação extrativa. Nesta técnica, um terceiro componente é adicionado à mistura para interferir no equilíbrio de fase do líquidovapor (ELV), enriquecendo a fração de álcool obtida no final da destilação, ou mesmo quebrando o azeótropo (Souza et al., 2017). 


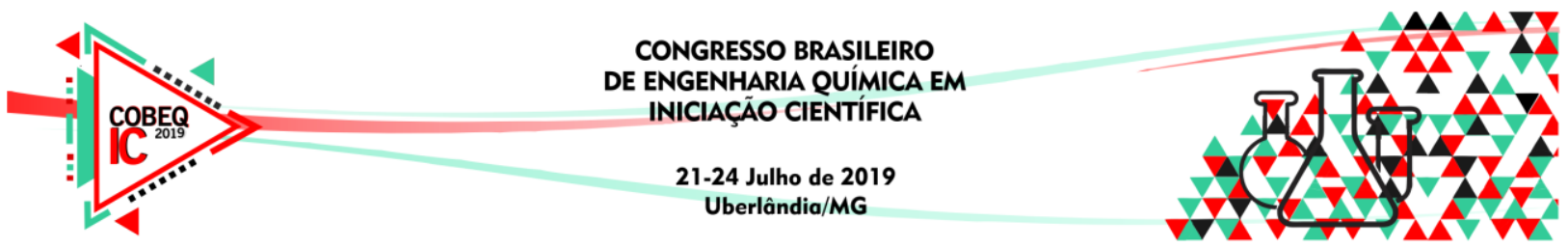

Para um sistema de etanol-água existem diversos trabalhos que comprovam a eficiência de compostos inorgânicos, como sais ou solventes orgânicos, como a glicerina, para a quebra do azeótropo. Porém há poucos dados na literatura referentes ao processo com o Isopropanol. É importante apontar também, que o glicerol é produzido como um subproduto na reação de transesterificação durante a produção de biodiesel. Devido à demanda global de alternativas mais verdes para petroquímicos e combustíveis derivados de petróleo, o crescimento de indústrias oleoquímicas e de biocombustíveis gerou um excedente de glicerol, inundando o mercado de produtos químicos (Pagliaro, 2017). Portanto, um uso alternativo deste subproduto é explorado neste documento.

Frente a isso, o presente trabalho teve como objetivo medir os dados do equilíbrio líquido-vapor (ELV) para o sistema binário isopropanol-água e para os sistemas ternários de isopropanol-água-glicerol e isopropanol-água-sal. Além disso, objetivou avaliar a influência da adição desses compostos no equilíbrio de fases e sua possível eficiência no uso de destilação extrativa através da curva de equilíbrio, medindo os dados sob diferentes concentrações de glicerol e dos sais.

\section{MATERIAIS E MÉTODOS}

\subsection{Materiais}

Para o preparo das soluções foi utilizado álcool isopropílico PA (PROQUIMIOS Comércio e Indústria Ltda., pureza mínima de 0,995) e água destilada. Como terceiro componente, usou-se a glicerina (PROQUIMIOS Comércio e Indústria Ltda., pureza mínima de $99,5 \%$ ) e acetatos de sódio anidro e potássio (Vetec Química Fina Ltda., pureza mínima de 99\%).

\subsection{Aparato Experimental e Análise das Amostras}

O procedimento experimental foi feito utilizando um ebuliômetro de borosilicato do tipo Othmer, como representado na Figura 1. Este ebuliômetro é composto por uma célula de equilíbrio (B), dois condensadores (C e D), duas saídas para retirada das amostras das fases líquida e vapor (A e E, respectivamente) e uma saída para o meio externo (F) para garantir a pressão atmosférica no interior do sistema. Foram acoplados um termômetro e um termopar aos pontos $\mathrm{A}$ e $\mathrm{G}$ para medição das temperaturas das fases líquido e vapor, respectivamente.

A composição das amostras foi determinada utilizando um densímetro digital (GEHAKA, modelo DSL 920), o qual tem uma incerteza na medida de $\pm 0,0001 \mathrm{~g} / \mathrm{cm}^{3}$. Os valores de massa específica obtidos foram comparados com uma curva de calibração previamente construída, variando a composição do sistema binário Isopropanol-água com composição de 0 a 1,0. Essa curva de calibração foi utilizada para os sistemas ternários, visto que tanto os sais quanto o glicerol possuem o ponto de fusão e ebulição muito superiores à água e o álcool e, consequentemente, não são vaporizadas.

\subsection{Metodologia Experimental}




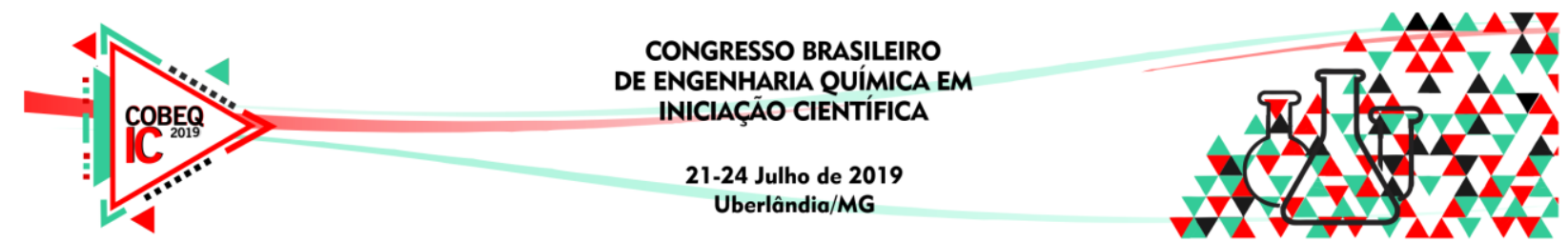

Os ensaios experimentais foram realizados para os sistemas ternários com as composições variando de 0,1 a 0,99 . As frações mássicas de sal variaram de $5 \%$ a $10 \%$ e para o glicerol foram utilizadas as frações mássicas de $10 \%$ e $20 \%$.

Figura 1 - Diagrama esquemático do ebuliômetro tipo Othmer

Fonte: Adaptado de Souza et al., 2013.

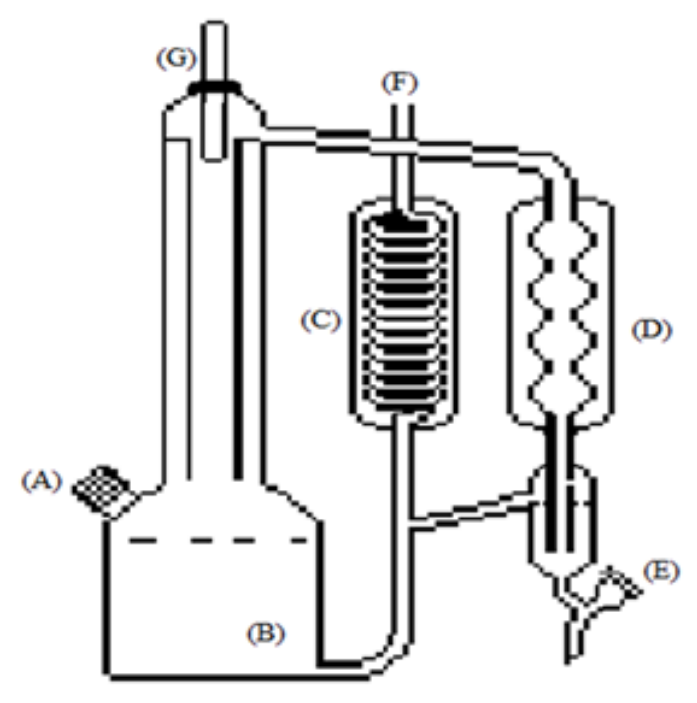

O procedimento experimentou iniciou com a alimentação da solução no ebuliômetro e, então, promoveu-se o aquecimento em chapa de aquecimento. A temperatura foi monitorada continuamente e a amostra somente foi analisada quando a temperatura do ponto de bolha permaneceu estável por mais de $30 \mathrm{~min}$. As amostras foram então levadas para a análise no densímetro. Cada ponto foi medido em triplicata e os resultados apresentados são a média das triplicatas.

\section{RESULTADOS E DISCUSSÃO}

Inicialmente, a fim de testar a precisão dos procedimentos e aparatos utilizados, foram realizados experimentos preliminares com o sistema binário isopropanol-água, onde as composições molares variaram de 0,1 a 0,9 . Os resultados obtidos desses ensaios foram comparados com os obtidos por Brunjes e Bogart (1943), como mostrado na Figura 2. Podese observar que as curvas apresentaram uma boa similaridade, apontando uma boa precisão dos equipamentos utilizados. O desvio médio relativo obtido foi de $9,81 \%$ para composição e $1,01 \%$ para a temperatura, e com isso, devido aos baixos desvios encontrados, considerou-se a metodologia utilizada validada.

Figura 2 - Equilíbrio Líquido-Vapor do sistema Isopropanol ${ }^{(1)}$-Água ${ }^{(2)}$ 

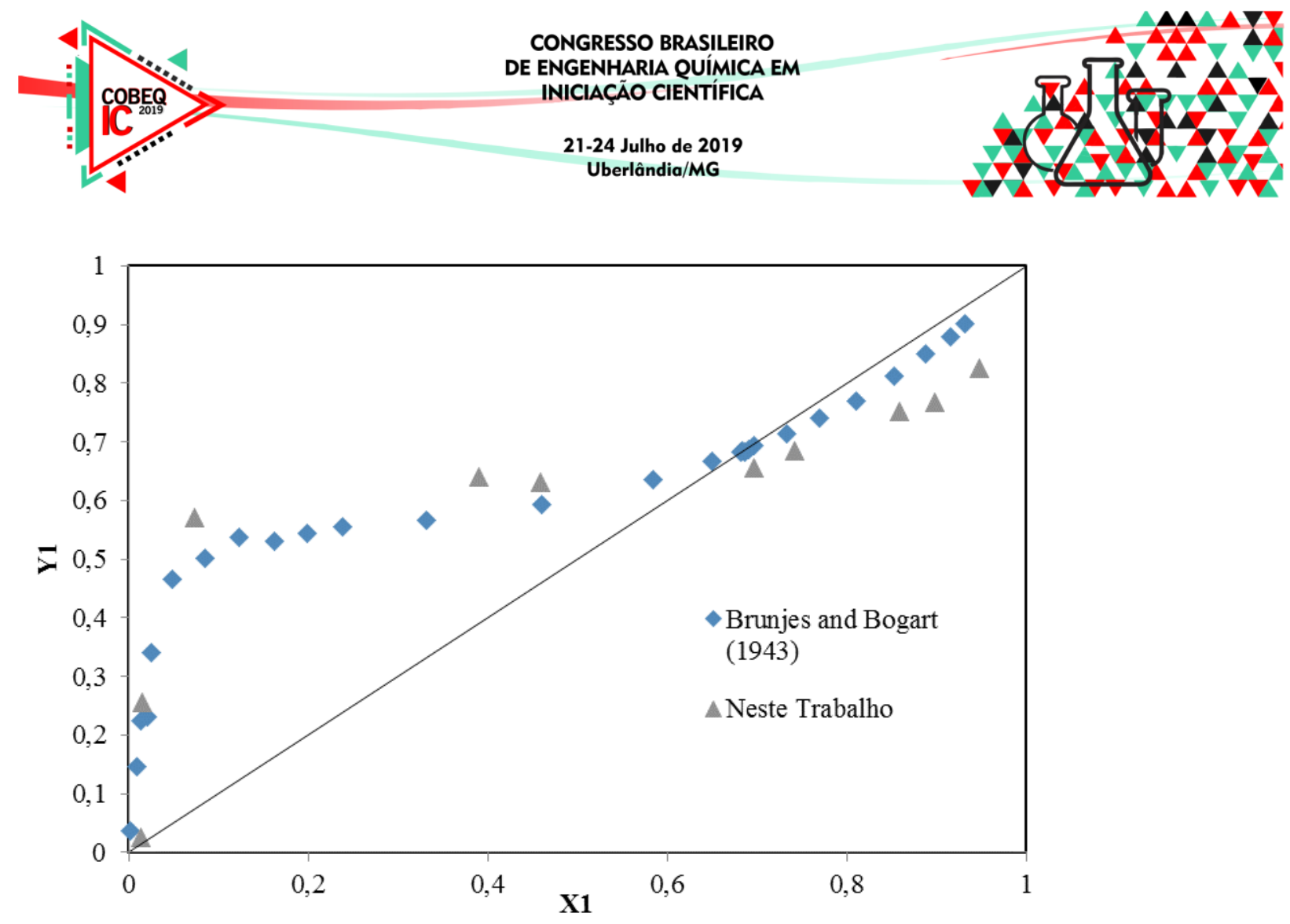

\subsection{Dados do ELV para os sistemas ternários:}

$\mathrm{Na}$ Tabela 1 podem ser observados os dados experimentais do ELV para o sistema ternário isopropanol-água-acetato de sódio, para a fração mássica de 5\% do sal. Pode-se perceber um enriquecimento da fase vapor e o deslocamento do azeótropo para frações maiores de 0,9 de álcool. O mesmo comportamento foi observado para o acetato de potássio para ambas as frações mássicas de 5 e $10 \%$ do sal. Porém, o aumento da quantidade de sal não produziu um maior enriquecimento do álcool na fase vapor.

Na Tabela 2 tem-se os dados para o ELV do sistema com o glicerol. Como para os sais, observou-se o enriquecimento e a quebra do azeótropo para frações maiores que 0,9 . Similarmente ao caso do sal de potássio, o aumento da fração mássica de glicerol acima de $20 \%$ não resultou em um enriquecimento significativo. Comparando os resultados obtidos pelos experimentos com glicerol e os sais, percebe-se que as frações de $20 \%$ de glicerol e $5 \%$ de acetato de sódio apresentaram os melhores resultados, sendo o acetato considerado mais eficiente, devido a uma maior composição alcóolica na fase vapor.

Os desvios padrões médios obtidos para a triplicata dos dados experimentais estão apresentados na Tabela 3. Foram obtidos baixos valores para os desvios de composição, mas os de temperatura foram mais elevados.

$\mathrm{Na}$ Tabela 4 estão representados os valores encontrados para a volatilidade relativa $\left(\alpha_{12}\right)$ para os sistemas ternários. Pode-se perceber, ao comparar os resultados, que houve um aumento significativo da volatilidade do álcool com a adição do glicerol ou dos sais. Tal fato demostra mais uma vez a possível aplicação dos co-solventes utilizados. 
Tabela 1 - Dados do ELV para os sistemas com sais

\begin{tabular}{|c|c|c|c|c|c|c|}
\hline & \multicolumn{2}{|c|}{ AcK 5\% } & \multicolumn{2}{c|}{ AcK 10\% } & \multicolumn{2}{c|}{ AcNa 5\% } \\
\hline $\mathrm{X}$ & $\mathrm{Y}$ & $\mathrm{T}\left({ }^{\circ} \mathrm{C}\right)$ & $\mathrm{Y}$ & $\mathrm{T}\left({ }^{\circ} \mathrm{C}\right)$ & $\mathrm{Y}$ & $\mathrm{T}\left({ }^{\circ} \mathrm{C}\right)$ \\
\hline 0,1 & 0,6023 & 81,60 & 0,5967 & 81,59 & 0,6569 & 81,33 \\
\hline 0,2 & 0,6387 & 80,95 & 0,6469 & 80,86 & 0,6729 & 81,00 \\
\hline 0,3 & 0,6466 & 80,83 & 0,6341 & 80,72 & 0,6910 & 80,69 \\
\hline 0,4 & 0,6686 & 80,66 & 0,6702 & 81,03 & 0,7174 & 80,51 \\
\hline 0,5 & 0,6867 & 80,66 & 0,7093 & 80,57 & 0,7369 & 80,35 \\
\hline 0,65 & 0,7556 & 80,63 & 0,7645 & 80,84 & 0,7843 & 80,57 \\
\hline 0,75 & 0,7711 & 80,84 & 0,8059 & 80,99 & 0,8176 & 80,71 \\
\hline 0,8 & 0,8132 & 80,97 & 0,8299 & 81,21 & 0,8403 & 80,77 \\
\hline 0,9 & 0,8696 & 81,30 & 0,8757 & 81,71 & 0,8913 & 81,50 \\
\hline 0,95 & 0,9132 & 82,55 & 0,9215 & 81,99 & 0,9516 & 81,96 \\
\hline 0,99 & 0,9492 & 82,34 & 0,9238 & 82,18 & 0,9795 & 82,18 \\
\hline \multicolumn{7}{|c|}{ Para AcNa 5\% u(T/ $\left./{ }^{\circ} \mathrm{C}\right)=2,4849 \mathrm{e} \mathrm{u}(\mathrm{Y})=0,0031$} \\
\hline
\end{tabular}

Tabela 2 - dados do ELV para o sistema com glicerol

\begin{tabular}{|c|c|c|c|c|}
\hline & \multicolumn{2}{|c|}{ Gli $10 \%$} & \multicolumn{2}{c|}{ Gli $20 \%$} \\
\hline $\mathrm{X}$ & $\mathrm{Y}$ & $\mathrm{T}\left({ }^{\circ} \mathrm{C}\right)$ & $\mathrm{Y}$ & $\mathrm{T}\left({ }^{\circ} \mathrm{C}\right)$ \\
\hline 0,1 & 0,4578 & 86,37 & 0,4664 & 86,26 \\
\hline 0,2 & 0,6623 & 81,52 & 0,6620 & 81,48 \\
\hline 0,3 & 0,6682 & 81,10 & 0,6620 & 81,53 \\
\hline 0,4 & 0,6867 & 80,74 & 0,7177 & 80,68 \\
\hline 0,5 & 0,7105 & 80,53 & 0,7346 & 80,64 \\
\hline 0,65 & 0,7744 & 80,32 & 0,7926 & 80,52 \\
\hline 0,75 & 0,8282 & 80,66 & 0,8523 & 80,79 \\
\hline 0,8 & 0,8416 & 80,69 & 0,8788 & 80,99 \\
\hline 0,9 & 0,9204 & 81,12 & 0,9397 & 81,47 \\
\hline 0,95 & 0,9517 & 81,82 & 0,9646 & 81,92 \\
\hline 0,99 & 0,9617 & 82,03 & 0,9785 & 81,89 \\
\hline \multicolumn{4}{|c|}{ Para $10 \% \mathrm{u}\left(\mathrm{T} /{ }^{\circ} \mathrm{C}\right)=3,877 \mathrm{e} \mathrm{u}(\mathrm{Y})=0,00293$} \\
\hline
\end{tabular}

Tabela 3 - Desvio padrão médio das triplicatas em relação às variáveis

\begin{tabular}{|c|c|c|c|c|c|c|c|c|c|}
\hline \multicolumn{2}{|c|}{ Gli $10 \%$} & \multicolumn{2}{c|}{ Gli 20\% } & \multicolumn{2}{c|}{ AcK 5\% } & \multicolumn{2}{c|}{ AcK 10\% } & \multicolumn{2}{c|}{ AcNa 5\% } \\
\hline DP Y & DP T & DP Y & DP T & DP Y & DP T & DP Y & DP T & DP Y & DPM T \\
\hline 0,0132 & 0,1963 & 0,0131 & 0,1716 & 0,0087 & 0,1710 & 0,0194 & 0,2131 & 0,0193 & 0,1292 \\
\hline
\end{tabular}




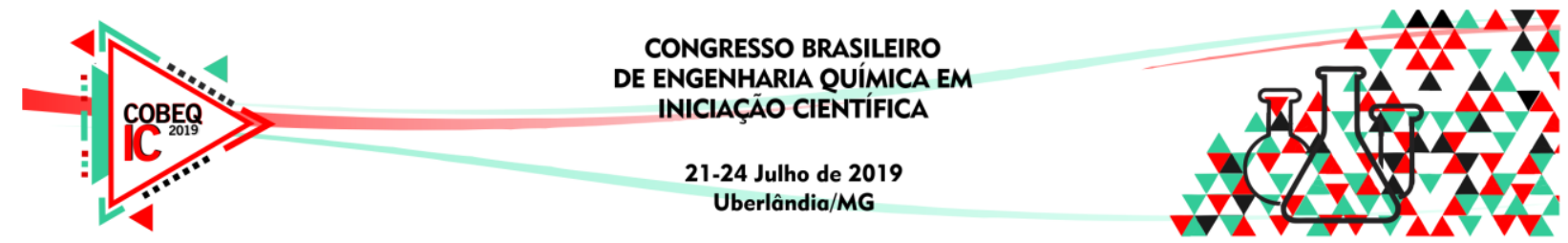

Tabela 4 - Volatilidades relativas dos sistemas para os diferentes solventes

\begin{tabular}{|c|c|c|c|c|c|c|}
\hline & \multicolumn{7}{|c|}{$\alpha_{12}$} \\
\hline X & gli 10\% & gli 20\% & AcK 5\% & AcK 10\% & AcNa 5\% & $\begin{array}{c}\text { Sem } \\
\text { sal }\end{array}$ \\
\hline 0,1 & 7,598 & 7,867 & 13,628 & 13,317 & 17,231 & 3,106 \\
\hline 0,2 & 7,845 & 7,835 & 7,073 & 7,328 & 8,227 & 5,305 \\
\hline 0,3 & 4,700 & 4,570 & 4,270 & 4,043 & 5,218 & - \\
\hline 0,4 & 3,287 & 3,813 & 3,026 & 3,048 & 3,808 & 2,672 \\
\hline 0,5 & 2,455 & 2,768 & 2,192 & 2,440 & 2,802 & 1,702 \\
\hline 0,65 & 1,848 & 2,058 & 1,389 & 1,458 & 1,633 & 1,171 \\
\hline 0,75 & 1,607 & 1,924 & 1,123 & 1,384 & 1,494 & 1,006 \\
\hline 0,8 & 1,328 & 1,812 & 1,089 & 1,220 & 1,315 & 0,824 \\
\hline 0,9 & 1,285 & 1,731 & 0,741 & 0,783 & 0,911 & 0,524 \\
\hline 0,95 & 1,037 & 1,434 & 0,554 & 0,618 & 1,035 & - \\
\hline 0,99 & 0,253 & 0,460 & 0,189 & 0,122 & 0,483 & - \\
\hline
\end{tabular}

Sendo, Gly - Glicerol, AcK - Acetato de Potássio, AcNa - Acetato de Sódio, u(T/ $\left.{ }^{\circ} \mathrm{C}\right)$ e $\mathrm{u}(\mathrm{Y})$ as incertezas das medições de temperatura e composição da fase vapor respectivamente, $\mathrm{X}$ a composição da fase líquida e $\mathrm{Y}$ a composição da fase vapor.

\section{CONCLUSÃO}

Nesse trabalho foi possível gerar novos dados de ELV, corroborando os resultados obtidos por Brunjes e Bogart (1943). O sal acetato de sódio apresentou os melhores resultados quando comparado com o sal de potássio e o glicerol. O sistema com glicerol $20 \%$ apresentou resultados similares com o de sal de sódio, sendo levemente menos eficiente, porém ainda é um componente mais promissor que os sais, visto o excesso do mesmo no mercado, devido à alta produção de biodiesel e, consequentemente, do glicerol como subproduto.

\section{REFERÊNCIAS BIBLIOGRÁFICAS}

BRUNJES, A. S.; BOGART, M. J. P. Vaporliquid equilibria for commercially important systems of organic solvents, Ind. Eng. Chem., 35, 255 - 260, 1943.

GOMES, G. C. C. Métodos de preparação industrial de solventes e reagentes químicos: Isopropanol (CAS 67-63-0). Rev. Virtual Quim., v. 8, n. 6, p. 2138-2146, 2016.

SOUZA, W. L. R.; SILVA, C. S.; MELEIRO, L. A. C.; MENDES, M. F. Vapor-liquid equilibrium of the (water + ethanol + glycerol) system: experimental and modelling data at normal pressure. J. Chem. Thermodyn., 67, 106-111, 2013.

PAGLIARO, M. Glycerol: The renewable Platform Chemical. Elsevier, 1-21, 2017.

MACHADO, M. V. C.; SANTOS, D. A.; BARROZO, M. A. S.; DUARTE, C. R. Experimental and numerical study of grinding media flow in a ball mill. Chem. Eng. Technol., v. 40, p. 1835-1843, 2017. 